\title{
Dinâmica da comunidade arbórea em uma floresta estacional semidecidual sob queimadas recorrentes ${ }^{1}$
}

Karine da Silva Peixoto ${ }^{2}$, Maryland Sanchez ${ }^{3}$, Fernando Pedroni ${ }^{3}$, Michele Novaes Ribeiro ${ }^{4}$, Kátia Gomes Facure ${ }^{5}$, Vera Lucia Gomes-Klein ${ }^{6}$ e Frederico Augusto Guimarães Guilherme ${ }^{7,8}$

Recebido em 29/09/2011. Aceito em 18/06/2012

\section{RESUMO}

(Dinâmica da comunidade arbórea em uma floresta estacional semidecidual sob queimadas recorrentes). Os efeitos do fogo sobre a mortalidade de árvores podem alterar a composição e estrutura da vegetação, dependendo da intensidade, frequência e duração das queimadas. Monitoramos áreas de floresta sujeitas a diferentes frequências de fogo no Parque Estadual da Serra Azul, Barra do Garças, MT: 0,9 ha queimaram em 2007 (Q1) e 0,9 ha em 2005 e 2007 (Q2). A dinâmica foi referente ao intervalo médio de 2,02 anos, de forma que o primeiro levantamento (T1) ocorreu em outubro/2006-maio/2007 e o segundo levantamento (T2) em março/2009, considerando indivíduos com PAP $\geq 15 \mathrm{~cm}$. A diversidade ( $\left.\mathrm{H}^{\prime}\right)$ e a riqueza de espécies (estimada por Jackknife) foram maiores em Q2, nos dois levantamentos. Ocorreu a diminuição significativa na densidade em Q1 e Q2, mas a proporção de indivíduos mortos foi maior em Q1. Os parâmetros da dinâmica baseados no número de indivíduos e na área basal não diferiram entre Q1 e Q2. O aumento da diversidade na área sujeita a maior frequência de queimadas pode ser explicada pela hipótese de distúrbio intermediário. Entretanto, apesar da mortalidade e recrutamento não terem diferido entre Q1 e Q2, as altas taxas de mudança, independentes da frequência do fogo, sugerem futuras alterações florísticas e estruturais na floresta, caso as queimadas continuem ocorrendo na área.

Palavras-chave: dinâmica florestal, distúrbios, incêndios florestais, mortalidade

\begin{abstract}
(Tree community dynamics in a semideciduous forest under recurrent fires). The effects of fire on tree mortality can change floristic and forest structure depending on intensity, frequency and the length of a fire. Areas of semideciduous forest in Parque Estadual da Serra Azul, Barra do Garças (MT, Brazil), exposed to different frequencies of fire, were monitored: 0.9 ha burned in 2007 (Q1) and 0.9 ha in 2005 and 2007 (Q2). The dynamics were based on the average interval of 2.02 years between T1 (outubro/2006-maio/2007) and T2 (March/2009), including individuals with PAP $\geq 15 \mathrm{~cm}$. Diversity (H') and species richness (estimated by Jackknife) were higher in Q2, in both at T1 and T2. The decrease of tree density between surveys was significant for Q1 and Q2, but the proportion of deaths was higher in Q1. There were no differences in the dynamic parameters between Q1 and Q2 when considering both the number of individuals and basal area. The increase of diversity in Q2 may be partially explained by the hypothesis of intermediate disturbance. However, despite the absence of differences in recruitment and mortality between Q1 and Q2, the high turnover rates, independent of fire frequency, suggest future changes in the flora and structure of the forest if fire continues to be frequent in the area.
\end{abstract}

Key words: forest dynamics, disturbances, forest fires, mortality

\footnotetext{
${ }^{1}$ Parte da dissertação de Mestrado da primeira Autora

${ }^{2}$ Universidade Federal de Goiás, Programa de Pós-Graduação em Ecologia e Evolução, Goiânia, GO, Brasil

${ }^{3}$ Universidade Federal de Mato Grosso, Instituto de Ciências Biológicas e da Saúde, Pontal do Araguaia, MT, Brasil

${ }^{4}$ Universidade do Estado de Mato Grosso, Programa de Pós-Graduação em Ecologia e Conservação, Nova Xavantina, MT, Brasil

${ }^{5}$ Universidade Federal de Uberlândia, Faculdade de Ciências Integradas do Pontal, Ituiutaba, MG, Brasil

${ }^{6}$ Universidade Federal de Goiás, Campus Samambaia, Goiânia, GO, Brasil

${ }^{7}$ Universidade Federal de Goiás, Campus de Jataí, Jataí, GO, Brasil

${ }^{8}$ Autor para correspondência: fredericoagg@gmail.com
} 


\section{Introdução}

O fogo pode alterar a estrutura, a composição florística e o crescimento das plantas, limitando o recrutamento de novas espécies e, dessa maneira, causando redução da densidade de árvores (Woods 1989; Cochrane \& Schulze 1999). A recuperação da vegetação após o fogo pode variar dependendo da intensidade e duração do incêndio (Keeley et al. 2003). Em alguns casos, os incêndios podem inibir o ciclo de regeneração da floresta (Kennard et al. 2002; Laurance 2003; Otterstrom \& Schwartz 2006), enquanto em outros esses distúrbios, quando em intensidade intermediária, podem ser importantes para a manutenção de um grande número de espécies (Hubbell et al. 1999), uma vez que provoca a reversão das comunidades a estados sucessionais iniciais, nos quais espécies previamente excluídas por competição, voltam a se estabelecer (Sheil \& Burslem 2003).

Características individuais das plantas, como sua anatomia e fisiologia, são fundamentais para determinar a sobrevivência desses organismos após o fogo (Bond \& Wilgen 1996). Nas formações savânicas do Cerrado, raízes profundas, folhas e súber espessos são características adaptativas que auxiliam as plantas a resistirem às altas temperaturas durante as queimadas. Já nas florestas, a maioria das árvores possui casca pouco espessa, resultando em alta mortalidade (Uhl \& Kauffman 1990). Em alguns casos, a mortalidade pode não ocorrer pela ação direta das chamas, mas como resultado da desidratação da copa devido ao aumento da temperatura, ou ainda pela perda do volume das raízes (Ivanauskas et al. 2003). Além disso, sabe-se que o fogo em formações florestais afeta principalmente os indivíduos mais jovens, uma vez que os indivíduos com diâmetro maior têm grande capacidade de sobreviver ao contato com as chamas (Cochrane \& Schulze 1999). Mesmo que algumas espécies tenham elevado grau de resistência aos incêndios, apresentando baixa mortalidade e rápida rebrota após fogo, tais características não são suficientes para garantir a persistência das comunidades florestais quando esses distúrbios são frequentes (Hoffmann \& Solbrig 2003).

Estudos de longo prazo acompanham as mudanças que ocorrem continuamente na comunidade florestal e auxiliam no entendimento dos processos ecológicos relacionados ao crescimento, recrutamento e mortalidade (Swaine et al. 1990; Braga \& Rezende 2007; Silva \& Araújo 2009). Embora difíceis de serem mantidos, esses monitoramentos são essenciais para o desenvolvimento e testes de hipóteses sobre os processos e as taxas de recuperação após perturbações, tanto antrópicas como naturais (Taylor et al. 2008).

Muitos estudos abordam a dinâmica das florestas tropicais (Lang \& Knight 1983; Lieberman et al. 1985; Denslow 1987; Swaine et al. 1990; Korning \& Balslev 1994; Sheil \& May 1996; Laurance et al. 1998; Holl 1999; DeWalt et al. 2003; Lewis et al. 2004; Saiter et al. 2011). Especificamente no Brasil, florestas semidecíduas, têm sido estudadas com relativa frequência (Oliveira-Filho et al. 1997; Nascimento et al. 1999; Chagas et al. 2001; Guilherme et al. 2004; Appolinário et al. 2005; Oliveira-Filho et al. 2007; Paiva et al. 2007; Higuchi et al. 2008; Silva \& Araujo 2009). No entanto, ainda são raros os estudos que analisam alterações estruturais e monitoram o desenvolvimento pós-fogo em florestas (Silva et al. 2005; Melo et al. 2007; Balch et al. 2008).

Baseados na ocorrência de dois incêndios florestais em 2005 e 2007 avaliamos os impactos do fogo sobre a estrutura, composição florística e dinâmica da comunidade arbórea na floresta estacional semidecidual do Parque Estadual da Serra Azul. O incêndio de 2005 atingiu apenas uma parte da floresta, enquanto em 2007 toda a floresta foi queimada de forma que metade das unidades amostrais queimaram duas vezes $(\mathrm{Q} 2)$ e a outra metade queimou apenas uma vez (Q1). Para fins deste estudo, consideramos que a homogeneidade pedológica e topográfica onde a floresta está instalada permitiu considerar o fogo como o fator mais importante para gerar alterações estruturais na comunidade arbórea. Nesse sentido, buscamos responder às seguintes perguntas: 1) $O$ fogo interfere na composição, diversidade e riqueza da comunidade florestal? Como espécies florestais são sensíveis ao fogo, espera-se que ocorram perdas de espécies com consequente alteração da composição, diversidade e riqueza. 2) O fogo altera a densidade da comunidade? Espera-se a redução do número de árvores em áreas com maior frequência de queimadas em função da mortalidade dos indivíduos mais vulneráveis às injúrias causadas pelo fogo. 3) As taxas de mortalidade e recrutamento observadas em Q1 diferem daquelas observadas em Q2? A taxa de mortalidade deve ser maior em Q2 e o recrutamento maior em Q1 devido a diferente incidência de queimadas nas duas áreas. 4) $\mathrm{A}$ área com maior frequência de queimadas é mais instável considerando o equilíbrio entre taxas de mortalidade e recrutamento? O padrão esperado na dinâmica de florestas em avançado estágio de sucessão é de equilíbrio entre as taxas de recrutamento/mortalidade, assim a área mais perturbada (Q2) deve apresentar maior instabilidade. 5) O fogo afeta a estrutura de tamanho (diâmetro e altura) da comunidade? Considerando que indivíduos maiores são menos suscetíveis ao fogo (suas copas elevadas ficam fora do alcance das chamas e seus troncos maiores levam mais tempo para aquecer), espera-se que a mortalidade seja maior entre indivíduos pertencentes às menores classes de tamanho, provocando alterações na estrutura de tamanho pela redução de indivíduos menores nas áreas com maior frequência de queimadas.

\section{Material e métodos}

\section{Área de estudo}

O presente estudo foi realizado no Parque Estadual da Serra Azul (PESA), Barra do Garças, MT (1552'S e $\left.51^{\circ} 16^{\prime} \mathrm{W}\right)$. O PESA ocupa uma área de 11.000 ha e apresenta altitude média de $560 \mathrm{~m}$. O clima da região, Aw na 
classificação de Köppen, caracteriza-se por duas estações bem definidas: uma quente e chuvosa (outubro a abril) e outra seca (maio a setembro). A precipitação média anual é $1528 \mathrm{~mm}$ e a temperatura média $25,5^{\circ} \mathrm{C}$ (Pirani et al. 2009).

$\mathrm{O}$ cerrado rupestre e o cerrado sentido restrito são as principais formações presentes no PESA, no entanto, existem também fisionomias campestres, florestas de galeria e florestas semidecíduas. O levantamento foi conduzido em uma floresta estacional semidecidual (15051'07,9'S e $52^{\circ} 14^{\prime} 19,6^{\prime \prime} \mathrm{W}$ ) que apresenta relevo com inclinação entre $10^{\circ}$ e $30^{\circ}$ e localiza-se nas partes mais altas do PESA (648 $\mathrm{m})$. Essa floresta e as demais fitofisionomias do PESA são ocasionalmente atingidas por incêndios, sendo que as queimadas mais recentes ocorreram em setembro de 2005 e outubro de 2007. O fogo oriundo das atividades humanas tem origem principalmente nas propriedades localizadas na divisa do PESA e são decorrentes da queima de pastagens na área rural e de lixo no perímetro urbano (FEMA 2000).

O trecho de floresta estacional estudado está localizado em uma área ambientalmente homogênea, tanto pedologicamente como topograficamente, e é cortado por uma estrada de terra que, no incêndio de 2005, funcionou como um aceiro, impedindo a propagação do fogo em um dos lados da floresta. No entanto, no incêndio de 2007, devido à prolongada estação seca e o consequente acúmulo de serapilheira, a estrada não foi suficiente para evitar a propagação do fogo, o qual atingiu toda a floresta em ambos os lados da estrada.

\section{Procedimentos de campo}

Para a realização do estudo, após o incêndio de 2005, foram demarcadas 180 parcelas permanentes de $10 \times 10 \mathrm{~m}$ agrupadas em seis blocos com 30 parcelas cada, totalizando uma área amostral de 1,8 ha. Três blocos ( 0,9 ha) estão localizados no trecho da floresta queimado apenas em 2007 e foram tratados no estudo como Q1. Os outros três blocos (0,9 ha) estão localizados no trecho da floresta queimado em 2005 e 2007 e foram tratados como Q2. Segundo fazendeiros que antes de 2008 ocupavam áreas no PESA, a parte da floresta correspondente a $\mathrm{Q} 2$, por estar posicionada em continuidade com as divisas de propriedades adjacentes ao Parque, queimou mais vezes ao longo dos anos que a área correspondente a Q1.

No primeiro levantamento (T1), realizado entre outubro de 2006 e maio de 2007, foram incluídos todos os indivíduos que apresentavam perímetro à altura do peito (PAP) igual ou superior a $15 \mathrm{~cm}$. Indivíduos com caules múltiplos foram incluídos quando pelo menos uma de suas ramificações possuísse PAP $\geq 15 \mathrm{~cm}$. Nesses casos foram anotadas as circunferências de todas as ramificações para o cálculo da área basal. Os indivíduos foram marcados com plaquetas de alumínio numeradas, tiveram os perímetros de seus caules medidos com fita métrica, altura máxima da copa estimada visualmente por comparação com uma vara de comprimento conhecido (vários estágios da tesoura de poda) e material botânico coletado para identificação. $\mathrm{O}$ material testemunho foi incorporado ao acervo do Herbário UFMT - Unidade do Campus Universitário do Araguaia. A identificação do material botânico foi realizada através de comparação com exsicatas já existentes em herbários e consultas à literatura.

No segundo levantamento (T2), realizado em março de 2009, foram adotados os mesmos critérios utilizados em T1. As árvores sobreviventes foram remedidas. Os indivíduos vivos que atingiram o critério mínimo de inclusão (recrutas) entre o primeiro e segundo levantamento receberam plaqueta de alumínio numerada, tiveram seus perímetros medidos, altura da copa estimada e material botânico coletado para identificação. Indivíduos registrados em T1 e não encontrados em T2 foram considerados mortos.

O intervalo de tempo $(t)$ transcorrido entre as amostragens variou entre 1,8 e 2,4 anos, dependendo da parcela analisada, sendo que a média entre T1 e T2 foi de 2,02 anos. Dessa forma, para os parâmetros de dinâmica, o intervalo de tempo foi calculado de duas maneiras: tempo por parcela, onde foi considerado o intervalo de tempo entre T1 e T2 para cada uma das 180 parcelas inventariadas; tempo por espécie, onde foi calculado o tempo médio considerando as datas de coletas de dados para todos os indivíduos de uma dada espécie.

\section{Análise dos dados}

A diversidade foi calculada pelo índice de diversidade de Shannon (H') (Magurran 1988), sendo comparados entre os tratamentos (Q1 e Q2) e entre os levantamentos (T1 e T2) através do teste $t$ (Hutcheson 1970). A riqueza de espécies esperada para Q1 e Q2 e para T1 e T2, foi calculada usando o estimador de riqueza Jackknife de primeira ordem, que prevê o número de espécies em uma área com base na frequência das espécies encontradas nela, ou seja, projeta o número total de espécies a partir da heterogeneidade da amostra (Chiarucci et al. 2003).

Para o cálculo dos parâmetros de dinâmica considerando o número de indivíduos foram obtidos: $\mathrm{N}_{1}=$ número de indivíduos inicial (indivíduos vivos presentes no primeiro levantamento); $\mathrm{N}_{2}=$ número de indivíduos final (indivíduos vivos presentes no segundo levantamento); $\mathrm{N}_{\mathrm{r}}$ = número de indivíduos recrutados entre o primeiro e o segundo levantamento; $\mathrm{N}_{\mathrm{m}}$ = número de indivíduos mortos entre o primeiro e o segundo levantamento. Para o cálculo dos parâmetros de dinâmica considerando a área basal foram obtidos: $\mathrm{AB}_{1}=$ área basal inicial (área basal viva no primeiro levantamento); $\mathrm{AB}_{2}=$ área basal final (área basal viva no segundo levantamento); $\mathrm{AB}_{\mathrm{m}}=$ área basal dos indivíduos mortos entre o primeiro e o segundo levantamento; $\mathrm{AB}_{\mathrm{d}}=$ área basal decrescida entre o primeiro e o segundo levantamento (área basal perdida por meio de quebra ou perda parcial do tronco); $\mathrm{AB}_{\mathrm{g}}=$ área basal ganha entre o primeiro e o segundo levantamento (incremento em área basal das árvores sobreviventes); $\mathrm{AB}_{\mathrm{r}}=$ área basal recrutada entre $\mathrm{o}$ primeiro e o segundo levantamento (área basal dos recrutas). 
As médias iniciais de densidade (número de indivíduos por parcela) e de área basal por parcela foram comparadas entre os tratamentos ( $\mathrm{Q} 1$ e Q2) usando o teste t para duas amostras independentes (Zar 1998). A variação temporal na densidade e na área basal foi avaliada pelo teste $\mathrm{t}$ pareado (Zar 1998). Diferenças entre os tratamentos na relação entre os valores iniciais e finais de densidade e de área basal foram testadas através de Análise de Covariância (ANCOVA), usando os valores iniciais como co-variável e os tratamentos como fator fixo (Zar 1998). As densidades de plantas por parcela foram transformadas em raiz quadrada antes das análises para alcançar os pressupostos de distribuição normal e homogeneidade de variâncias dos testes paramétricos (Zar 1998). As proporções de indivíduos que morreram entre os tempos T1 e T2 foram comparadas entre os tratamentos Q1 e Q2 pelo teste de Qui-quadrado (Zar 1998). A normalidade dos dados foi avaliada através do teste para normalidade de Shapiro-Wilk e a homogeneidade de variâncias pelo teste de F (Zar 1998). Para ambos os testes, foi usado o pacote estatístico $\mathrm{R}$ versão 2.10.1 ( $\mathrm{R}$ Development Core Team 2009). As demais análises foram feitas no programa SYSTAT 10 (SPSS, 2000). O nível de significância adotado foi de 5\%.

Foram calculados para a área total, Q1 e Q2 os seguintes parâmetros de dinâmica: taxas anuais médias de mortalidade $\mathrm{M}=\left\{1-\left[\left(\mathrm{N}_{1}-\mathrm{N}_{\mathrm{m}}\right) / \mathrm{N}_{1}\right]^{1 / t}\right\} \times 100$ e recrutamento $\mathrm{R}=[1-$ $\left.\left(1-\mathrm{N}_{\mathrm{r}} / \mathrm{N}_{2}\right)^{1 / \mathrm{t}}\right] \times 100$ de árvores individuais e as taxas anuais médias de perda $\mathrm{P}=\left\{1-\left[\left(\mathrm{AB}_{1}-\mathrm{AB}_{\mathrm{m}}-\mathrm{AB}_{\mathrm{d}}\right) / \mathrm{AB}_{1}\right]^{1 / t}\right\} \times 100$ e ganho $\mathrm{G}=\left\{1-\left[1-\left(\mathrm{AB}_{\mathrm{r}}+\mathrm{AB}_{\mathrm{g}}\right) / \mathrm{AB}_{2}\right]^{1 / t}\right\} \times 100$ de área basal por meio das expressões exponenciais, segundo Sheil et al. (2000); as taxas de mudança líquida tanto para número de indivíduos $\mathrm{Ch}_{\mathrm{N}}=\left[\left(\mathrm{N}_{2} / \mathrm{N}_{1}\right)^{1 / \mathrm{t}}-1\right] \times 100$ como para área basal $\mathrm{Ch}_{\mathrm{AB}}=\left[\left(\mathrm{AB}_{2} / \mathrm{AB}_{1}\right)^{1 / \mathrm{t}}-1\right] \times 100$, conforme Korning \& Balslev (1994); e as taxas de rotatividade ("turnover") para número de indivíduos $\left(T_{N}=(M+R) / 2\right)$ e para área basal $\left(\mathrm{T}_{\mathrm{AB}}=(\mathrm{P}+\mathrm{G}) / 2\right)$ também sugeridas por Korning \& Balslev (1994). As comparações dos parâmetros de dinâmica entre Q1 e Q2 foram feitas através de teste $\mathrm{t}$ (Zar 1998).

A dinâmica nas diferentes classes diamétricas foi avaliada considerando tanto o número de indivíduos como a área basal, os quais foram distribuídos em intervalos de classe com amplitudes crescentes com a finalidade de compensar o acentuado decréscimo da densidade nas classes de tamanho maiores (Appolinário et al. 2005; Oliveira-Filho et al. 2007; Guimarães et al. 2008). Além disso, histogramas de frequência contendo cinco classes de altura $(0+5 \mathrm{~m} ; 5$ - $10 \mathrm{~m} ; 10-15 \mathrm{~m} ; 15-20 \mathrm{~m} ;>20$ $\mathrm{m})$ foram elaboradas com o intuito de avaliar a distribuição dos indivíduos de acordo com seu tamanho. Para verificar se houve diferenças significativas na frequência de indivíduos (por classes de diâmetro e altura) e área basal (por classes de diâmetro) entre Q1 e Q2 e entre os levantamentos (T1 e T2) foi aplicado o teste Kolmogorov-Smirnov (Zar 1998).

Para descrever as variações temporais ocorridas nas classes de diâmetro e altura (considerando número de indivíduos e área basal) os indivíduos foram classificados em seis categorias. 1) Imigrantes: indivíduos sobreviventes, pertencentes a qualquer classe de tamanho, que cresceram ou diminuíram de tamanho e passaram a pertencer a uma determinada classe de tamanho no intervalo de tempo entre as amostragens. 2) Recrutas: indivíduos, não incluídos em T1, que cresceram, durante o intervalo de tempo entre as amostragens, atingindo o PAP mínimo de inclusão. 3) Emigrantes: indivíduos sobreviventes, pertencentes a uma determinada classe de tamanho, que cresceram ou diminuíram de tamanho e que passaram a pertencer a outras classes de tamanho no intervalo de tempo entre as amostragens. 4) Mortos: indivíduos que morreram no intervalo de tempo entre as amostragens. 5) Ingressantes: indivíduos que entraram (recrutas + imigrantes) em cada classe de tamanho no intervalo de tempo entre as amostragens. 6) Egressos indivíduos que saíram (mortos + emigrantes) de cada classe de tamanho (Lieberman et al. 1985).

Foram calculadas ainda as frequências esperadas de indivíduos mortos e de indivíduos vivos no segundo levantamento, utilizando-se a fórmula: $\mathrm{N}_{\text {esp }}$ classe $=\left(\mathrm{N}_{1}\right.$ classe $/ \mathrm{N}_{1}$ total $) \times \mathrm{N}_{2}$ total. Onde: $\mathrm{N}_{\text {esp }}$ classe é o número de indivíduos esperado por classe diamétrica; $\mathrm{N}_{1}$ classe é a contagem inicial de árvores na classe diamétrica; $\mathrm{N}_{1}$ total é a contagem inicial total (número de indivíduos inicial ou $\mathrm{N}_{1}$ ); e $\mathrm{N}_{2}$ total é a contagem final total (número de indivíduos final ou $\mathrm{N}_{2}$ ) (Guimarães et al. 2008). Nesse caso, para verificar se as frequências observadas em T2 foram diferentes das esperadas, utilizou-se o teste de Kolmogorov-Smirnov (Zar 1998).

\section{Resultados}

No primeiro levantamento (T1), foram encontradas 102 espécies, distribuídas em 87 gêneros e 41 famílias. No segundo levantamento (T2), devido à morte dos únicos indivíduos de Diospyros sericea e Miconia albicans, ambos localizados em Q2, a riqueza total diminuiu para 100 espécies, as quais foram distribuídas em 86 gêneros e 40 famílias (Tab. 1). Mesmo com a perda de duas espécies entre T1 e T2, o índice de diversidade $\left(\mathrm{H}^{\prime}\right)$ obtido para a área total não variou com o tempo, mantendo-se em 3,77 nats.ind. ${ }^{-1} \mathrm{em}$ ambos os levantamentos. O mesmo ocorreu em Q1 e em Q2, onde o índice de diversidade também não sofreu alterações no intervalo de tempo considerado (Tab. 2). Comparando-se as duas áreas, a diversidade ( $\left.\mathrm{H}^{\prime}\right)$ foi significativamente maior em Q2 do que em Q1, tanto em T1 $(\mathrm{t}=4,76 ; \mathrm{p}<0,001)$ como em T2 $(\mathrm{t}=4,46 ; \mathrm{p}<0,001)$ (Tab. 2). A riqueza de espécies estimada também foi maior em Q2 (T1: Jackknife 111,8 \pm 7,8; T2: Jackknife 109,8 \pm 8.8 ) quando comparada com Q1 (T1: Jackknife 96,9 $\pm 7,7$; T2: Jackknife 93,9 $\pm 7,2$ ) em ambos os levantamentos.

$\mathrm{O}$ número de árvores amostradas em T1 e T2 foi 2331 e 2144 indivíduos, respectivamente. Portanto, houve uma perda líquida de 187 indivíduos, como resultado da morte de 212 indivíduos e ingresso de apenas 25 árvores (Tab. 2). A densidade inicial de plantas foi maior no tratamento Q2 (14 
Tabela 1. Dinâmica das espécies lenhosas (ordenadas por Valor de Importância) amostradas na floresta semidecídua do Parque Estadual da Serra Azul, Barra do Garças, MT. $\mathrm{N}_{1}$ = número de indivíduos vivos no primeiro levantamento (T1); $\mathrm{N}_{2}$ = número de indivíduos vivos no segundo levantamento (T2); $\mathrm{N}_{\mathrm{m}}=$ número de indivíduos mortos entre $\mathrm{T} 1$ e T2; $\mathrm{N}_{\mathrm{r}}$ = número de indivíduos recrutados entre T1 e T2; Q1 = parcelas queimadas uma vez; Q2 = parcelas queimadas duas vezes; $\mathrm{M}=$ taxa de mortalidade; $\mathrm{R}=$ taxa de recrutamento. Valores de dinâmica foram apresentados para espécies com cinco ou mais indivíduos.

\begin{tabular}{|c|c|c|c|c|c|c|c|c|c|c|c|c|c|c|c|}
\hline \multirow{3}{*}{$\begin{array}{l}\text { Intervalo } \\
\text { entre T1 e } \\
\text { T2 (anos) }\end{array}$} & \multirow{3}{*}{ Espécies } & \multicolumn{10}{|c|}{ Número de Indivíduos } & \multicolumn{4}{|c|}{ Parâmetros de Dinâmica } \\
\hline & & \multicolumn{2}{|c|}{ Área Total } & \multicolumn{4}{|c|}{ Q1 } & \multicolumn{4}{|c|}{ Q2 } & \multicolumn{2}{|c|}{$\mathrm{M}(\%)$} & \multicolumn{2}{|c|}{$\mathrm{R}(\%)$} \\
\hline & & $\mathrm{N}_{1}$ & $\mathrm{~N}_{2}$ & $\mathrm{~N}_{1}$ & $\mathrm{~N}_{\mathrm{m}}$ & $\mathrm{N}_{\mathrm{r}}$ & $\mathrm{N}_{2}$ & $\mathrm{~N}_{1}$ & $\mathrm{~N}_{\mathrm{m}}$ & $\mathrm{N}_{\mathrm{r}}$ & $\mathrm{N}_{2}$ & Q1 & Q2 & Q1 & Q2 \\
\hline 1,99 & $\begin{array}{l}\text { Coussarea hydrangeifolia (Benth.) } \\
\text { Benth. \& Hook. f. }\end{array}$ & 251 & 227 & 136 & 15 & 2 & 123 & 115 & 13 & 2 & 104 & 5,70 & 5,85 & 0,82 & 0,97 \\
\hline 2,10 & Cordia sellowiana Cham. & 226 & 198 & 140 & 16 & 0 & 124 & 86 & 12 & 0 & 74 & 5,62 & 6,91 & 0,00 & 0,00 \\
\hline 2,04 & $\begin{array}{c}\text { Aspidosperma subincanum } \\
\text { Mart. ex A. DC. }\end{array}$ & 191 & 181 & 71 & 6 & 2 & 67 & 120 & 6 & 0 & 114 & 4,24 & 2,48 & 1,47 & 0,00 \\
\hline 1,98 & Calyptranthes lucida Mart. ex DC. & 93 & 85 & 21 & 3 & 0 & 18 & 72 & 5 & 0 & 67 & 7,49 & 3,57 & 0,00 & 0,00 \\
\hline 2,18 & Apuleia leiocarpa (Vogel) J.F. Macbr. & 83 & 62 & 46 & 18 & 0 & 28 & 37 & 3 & 0 & 34 & 20,37 & 3,80 & 0,00 & 0,00 \\
\hline 2,15 & Anadenanthera falcata (Benth.) Speg. & 68 & 64 & 39 & 3 & 1 & 37 & 29 & 2 & 0 & 27 & 3,65 & 3,27 & 1,27 & 0,00 \\
\hline 2,00 & Ocotea corymbosa (Meisn.) Mez & 65 & 56 & 40 & 5 & 0 & 35 & 25 & 4 & 0 & 21 & 6,46 & 8,35 & 0,00 & 0,00 \\
\hline 1,94 & Ecclinusa ramiflora Mart. & 64 & 64 & 52 & 2 & 1 & 51 & 12 & 0 & 1 & 13 & 2,00 & 0,00 & 1,20 & 4,04 \\
\hline 2,07 & Luehea grandiflora Mart. & 63 & 59 & 36 & 3 & 1 & 34 & 27 & 2 & 0 & 25 & 4,12 & 3,65 & 1,43 & 0,00 \\
\hline 1,91 & Hymenaea courbaril L. & 59 & 56 & 17 & 0 & 0 & 17 & 42 & 3 & 0 & 39 & 0,00 & 3,81 & 0,00 & 0,00 \\
\hline 1,94 & $\begin{array}{l}\text { Campomanesia eugenioides } \\
\text { (Cambess.) D. Legrand }\end{array}$ & 58 & 56 & 20 & 1 & 1 & 20 & 38 & 2 & 0 & 36 & 2,61 & 2,75 & 2,61 & 0,00 \\
\hline 1,90 & $\begin{array}{l}\text { Protium heptaphyllum } \\
\text { (Aubl.) Marchand }\end{array}$ & 55 & 51 & 22 & 3 & 0 & 19 & 33 & 1 & 0 & 32 & 7,43 & 1,61 & 0,00 & 0,00 \\
\hline 2,06 & Platypodium elegans Vogel & 54 & 54 & 22 & 0 & 1 & 23 & 32 & 1 & 0 & 31 & 0,00 & 1,53 & 2,13 & 0,00 \\
\hline 1,96 & Machaerium acutifolium Vogel & 53 & 50 & 16 & 2 & 0 & 14 & 37 & 1 & 0 & 36 & 6,59 & 1,39 & 0,00 & 0,00 \\
\hline 1,93 & Physocalymma scaberrimum Pohl & 52 & 51 & 27 & 2 & 1 & 26 & 25 & 0 & 0 & 25 & 3,91 & 0,00 & 2,01 & 0,00 \\
\hline 1,98 & Bauhinia longifolia D. Dietr. & 50 & 48 & 21 & 2 & 3 & 22 & 29 & 3 & 0 & 26 & 4,93 & 5,37 & 7,14 & 0,00 \\
\hline 2,10 & Ephedranthus sp. & 47 & 45 & 23 & 2 & 0 & 21 & 24 & 1 & 1 & 24 & 4,24 & 2,01 & 0,00 & 2,01 \\
\hline 1,93 & $\begin{array}{l}\text { Astronium fraxinifolium } \\
\text { Schott ex Spreng. }\end{array}$ & 46 & 46 & 17 & 0 & 0 & 17 & 29 & 0 & 0 & 29 & 0,00 & 0,00 & 0,00 & 0,00 \\
\hline 1,95 & Pouteria pachycalyx T.D. Penn. & 37 & 35 & 14 & 1 & 0 & 13 & 23 & 2 & 1 & 22 & 3,73 & 4,56 & 0,00 & 2,36 \\
\hline 2,09 & Inga cylindrica (Vell.) Mart. & 34 & 25 & 19 & 5 & 0 & 14 & 15 & 4 & 0 & 11 & 13,59 & 13,79 & 0,00 & 0,00 \\
\hline 1,94 & $\begin{array}{l}\text { Leptolobium araguaiense } \\
\text { Sch.Rodr. \& AM.G.Azevedo }\end{array}$ & 33 & 32 & 15 & 1 & 1 & 15 & 18 & 1 & 0 & 17 & 3,49 & 2,90 & 3,49 & 0,00 \\
\hline 1,96 & Pouteria torta (Mart.) Radlk. & 30 & 29 & 14 & 1 & 0 & 13 & 16 & 0 & 0 & 16 & 3,73 & 0,00 & 0,00 & 0,00 \\
\hline 1,97 & Rudgea viburnoides (Cham.) Benth. & 28 & 26 & 9 & 0 & 0 & 9 & 19 & 2 & 0 & 17 & 0,00 & 5,49 & 0,00 & 0,00 \\
\hline 1,96 & Maprounea guianensis Aubl. & 28 & 24 & 2 & 0 & 0 & 2 & 26 & 4 & 0 & 22 & 0,00 & 8,17 & 0,00 & 0,00 \\
\hline 1,98 & Matayba elaeagnoides Radlk. & 22 & 19 & 11 & 1 & 0 & 10 & 11 & 2 & 0 & 9 & 4,70 & 9,64 & 0,00 & 0,00 \\
\hline 1,96 & $\begin{array}{l}\text { Tabebuia impetiginosa } \\
\text { (Mart. ex DC.) Standl. }\end{array}$ & 20 & 19 & 11 & 1 & 0 & 10 & 9 & 0 & 0 & 9 & 4,75 & 0,00 & 0,00 & 0,00 \\
\hline 1,93 & Ormosia arborea (Vell.) Harms & 20 & 18 & 9 & 1 & 0 & 8 & 11 & 1 & 0 & 10 & 5,92 & 4,82 & 0,00 & 0,00 \\
\hline 1,97 & Virola sebifera Aubl. & 20 & 16 & 12 & 4 & 0 & 8 & 8 & 0 & 0 & 8 & 18,60 & 0,00 & 0,00 & 0,00 \\
\hline 2,04 & Apeiba tibourbou Aubl. & 19 & 18 & 8 & 0 & 0 & 8 & 11 & 1 & 0 & 10 & 0,00 & 4,56 & 0,00 & 0,00 \\
\hline 1,85 & Tabebuia roseoalba (Ridl.) Sandwith & 19 & 18 & 2 & 0 & 0 & 2 & 17 & 1 & 0 & 16 & 0,00 & 3,22 & 0,00 & 0,00 \\
\hline 1,95 & Cheiloclinium cognatum (Miers) A.C. Sm. & 17 & 18 & 7 & 0 & 0 & 7 & 10 & 0 & 1 & 11 & 0,00 & 0,00 & 0,00 & 4,77 \\
\hline 1,86 & Xylopia aromatica (Lam.) Mart. & 16 & 16 & 4 & 0 & 0 & 4 & 12 & 0 & 0 & 12 & 0,00 & 0,00 & 0,00 & 0,00 \\
\hline 1,97 & Qualea multiflora Mart. & 16 & 15 & 6 & 0 & 0 & 6 & 10 & 1 & 0 & 9 & 0,00 & 5,21 & 0,00 & 0,00 \\
\hline 1,91 & Swartzia macrostachya Benth. & 15 & 15 & 1 & 0 & 0 & 1 & 14 & 0 & 0 & 14 & 0,00 & 0,00 & 0,00 & 0,00 \\
\hline 1,91 & Pseudolmedia laevigata Trécul & 15 & 13 & 10 & 1 & 0 & 9 & 5 & 1 & 0 & 4 & 5,37 & 11,03 & 0,00 & 0,00 \\
\hline 1,89 & $\begin{array}{c}\text { Agonandra brasiliensis } \\
\text { Miers ex Benth. \& Hook. f. }\end{array}$ & 14 & 14 & 12 & 0 & 0 & 12 & 2 & 0 & 0 & 2 & 0,00 & 0,00 & 0,00 & 0,00 \\
\hline 1,85 & $\begin{array}{l}\text { Himatanthus sucuuba } \\
\text { (Spruce ex Müll. Arg.) Woodson }\end{array}$ & 13 & 14 & 7 & 0 & 1 & 8 & 6 & 0 & 0 & 6 & 0,00 & 0,00 & 6,96 & 0,00 \\
\hline
\end{tabular}


Tabela 1. Continuação.

\begin{tabular}{|c|c|c|c|c|c|c|c|c|c|c|c|c|c|c|c|}
\hline \multirow{3}{*}{$\begin{array}{l}\text { Intervalo } \\
\text { entre T1 e } \\
\text { T2 (anos) }\end{array}$} & \multirow{3}{*}{ Espécies } & \multicolumn{10}{|c|}{ Número de Indivíduos } & \multicolumn{4}{|c|}{ Parâmetros de Dinâmica } \\
\hline & & \multicolumn{2}{|c|}{ Área Total } & \multicolumn{4}{|c|}{ Q1 } & \multicolumn{4}{|c|}{ Q2 } & \multicolumn{2}{|c|}{$\mathrm{M}(\%)$} & \multicolumn{2}{|c|}{$\mathrm{R}(\%)$} \\
\hline & & $\mathrm{N}_{1}$ & $\mathrm{~N}_{2}$ & $\mathrm{~N}_{1}$ & $\mathrm{~N}_{\mathrm{m}}$ & $\mathrm{N}_{\mathrm{r}}$ & $\mathrm{N}_{2}$ & $\mathrm{~N}_{1}$ & $\mathrm{~N}_{\mathrm{m}}$ & $\mathrm{N}_{\mathrm{r}}$ & $\mathrm{N}_{2}$ & Q1 & Q2 & Q1 & Q2 \\
\hline 1,93 & Erythroxylum deciduum A. St.-Hil. & 13 & 12 & 9 & 1 & 0 & 8 & 4 & 0 & 0 & 4 & 5,92 & 0,00 & 0,00 & 0,00 \\
\hline 2,00 & $\begin{array}{c}\text { Terminalia brasiliensis } \\
\text { (Cambess. ex A. St.-Hil.) Eichler }\end{array}$ & 12 & 11 & 3 & 0 & 0 & 3 & 9 & 1 & 0 & 8 & 0,00 & 5,72 & 0,00 & 0,00 \\
\hline 1,96 & Maytenus robusta Reissek & 11 & 12 & - & - & - & - & 11 & 0 & 1 & 12 & - & 0,00 & - & 4,34 \\
\hline 1,97 & Guazuma ulmifolia Lam. & 11 & 10 & - & - & - & - & 11 & 1 & 0 & 10 & - & 4,72 & - & 0,00 \\
\hline 2,06 & $\begin{array}{l}\text { Nectandra grandiflora } \\
\text { Nees \& C. Mart. ex Nees }\end{array}$ & 11 & 8 & 4 & 1 & 0 & 3 & 7 & 2 & 0 & 5 & - & 15,07 & 0,00 & 0,00 \\
\hline 2,07 & Copaifera langsdorffii Desf. & 10 & 10 & 3 & 0 & 0 & 3 & 7 & 0 & 0 & 7 & 0,00 & 0,00 & 0,00 & 0,00 \\
\hline 2,06 & Guettarda viburnoides Cham. \& Schltdl. & 10 & 10 & - & - & - & - & 10 & 0 & 0 & 10 & - & 0,00 & - & 0,00 \\
\hline 1,92 & Myracrodruon urundeuva Allemão & 10 & 10 & - & - & - & - & 10 & 0 & 0 & 10 & - & 0,00 & - & 0,00 \\
\hline 1,96 & Byrsonima sericea DC. & 9 & 10 & 4 & 0 & 0 & 4 & 5 & 0 & 1 & 6 & 0,00 & . & 0,00 & 8,88 \\
\hline 2,00 & Eugenia stictopetala DC. & 9 & 10 & 5 & 0 & 0 & 5 & 4 & 0 & 1 & 5 & 0,00 & 0,00 & 0,00 & 10,56 \\
\hline 2,02 & Dilodendron bipinnatum Radlk. & 9 & 8 & - & - & - & - & 9 & 1 & 0 & 8 & - & 5,66 & - & 0,00 \\
\hline 2,02 & Diospyros brasiliensis Mart. ex Miq. & 9 & 8 & 4 & 0 & 0 & 4 & 5 & 1 & 0 & 4 & 0,00 & 10,46 & 0,00 & 0,00 \\
\hline 1,93 & Tabebuia ochracea A.H. Gentry & 9 & 8 & 5 & 0 & 0 & 5 & 4 & 1 & 0 & 3 & 0,00 & - & 0,00 & 0,00 \\
\hline 1,90 & Matayba guianensis Aubl. & 9 & 7 & 8 & 2 & 0 & 6 & 1 & 0 & 0 & 1 & 14,05 & 0,00 & 0,00 & 0,00 \\
\hline 1,90 & Callisthene fasciculata Mart. & 8 & 7 & 3 & 0 & 0 & 3 & 5 & 1 & 0 & 4 & 0,00 & - & 0,00 & 0,00 \\
\hline 1,93 & Casearia sylvestris Sw. & 8 & 7 & 4 & 0 & 0 & 4 & 4 & 1 & 0 & 3 & 0,00 & - & 0,00 & 0,00 \\
\hline 1,95 & Ouratea castaneifolia (DC.) Engl. & 7 & 7 & 5 & 0 & 0 & 5 & 2 & 0 & 0 & 2 & 0,00 & 0,00 & 0,00 & 0,00 \\
\hline 2,09 & Simarouba versicolor A. St.-Hil. & 7 & 7 & - & - & - & - & 7 & 0 & 0 & 7 & 0,00 & - & 0,00 & - \\
\hline 2,00 & Sterculia striata A. St.-Hil. \& Naudin & 7 & 7 & 2 & 0 & 0 & 2 & 5 & 0 & 0 & 5 & 0,00 & 0,00 & 0,00 & 0,00 \\
\hline 1,85 & Cupania vernalis Cambess. & 7 & 6 & 6 & 1 & 0 & 5 & 1 & 0 & 0 & 1 & 9,39 & 0,00 & 0,00 & 0,00 \\
\hline 2,09 & Eugenia sp. & 7 & 5 & 6 & 1 & 0 & 5 & 1 & 1 & 0 & 0 & 8,35 & - & 0,00 & 0,00 \\
\hline 1,95 & Coccoloba mollis Casar. & 7 & 4 & - & - & - & - & 7 & 3 & 0 & 4 & - & 24,95 & - & 0,00 \\
\hline 2,14 & Alibertia edulis (Rich.) A. Rich. ex DC. & 6 & 6 & 2 & 0 & 0 & 2 & 4 & 0 & 0 & 4 & 0,00 & 0,00 & 0,00 & 0,00 \\
\hline 1,84 & Andira anthelmia (Vell.) J.F. Macbr. & 6 & 6 & 3 & 0 & 0 & 3 & 3 & 0 & 0 & 3 & 0,00 & 0,00 & 0,00 & 0,00 \\
\hline 1,84 & Qualea dichotoma (Mart.) Warm. & 6 & 6 & 2 & 0 & 0 & 2 & 4 & 0 & 0 & 4 & 0,00 & 0,00 & 0,00 & 0,00 \\
\hline 1,80 & Dipteryx alata Vogel & 5 & 5 & 2 & 0 & 0 & 2 & 3 & 0 & 0 & 3 & 0,00 & 0,00 & 0,00 & 0,00 \\
\hline 2,00 & Indeterminada 01 & 5 & 5 & 1 & 0 & 0 & 1 & 4 & 0 & 0 & 4 & 0,00 & 0,00 & 0,00 & 0,00 \\
\hline 1,94 & Magonia pubescens A. St.-Hil. & 5 & 5 & 2 & 0 & 0 & 2 & 3 & 0 & 0 & 3 & 0,00 & 0,00 & 0,00 & 0,00 \\
\hline 1,80 & Sapium glandulatum (Vell.) Pax & 5 & 5 & 3 & 0 & 0 & 3 & 2 & 0 & 0 & 2 & 0,00 & 0,00 & 0,00 & 0,00 \\
\hline 2,09 & Trichilia pallida Sw. & 5 & 5 & 4 & 0 & 0 & 4 & 1 & 0 & 0 & 1 & 0,00 & 0,00 & 0,00 & 0,00 \\
\hline 2,38 & Cedrela fissilis Vell. & 5 & 4 & 3 & 0 & 0 & 3 & 2 & 1 & 0 & 1 & 0,00 & - & 0,00 & 0,00 \\
\hline 2,04 & Duguetia lanceolata A. St.-Hil. & 5 & 4 & 3 & 1 & 0 & 2 & 2 & 0 & 0 & 2 & - & 0,00 & 0,00 & 0,00 \\
\hline 2,44 & Acacia polyphylla DC. & 5 & 3 & 1 & 0 & 0 & 1 & 4 & 2 & 0 & 0 & 0,00 & - & 0,00 & 0,00 \\
\hline 1,80 & Cybistax antisyphilitica (Mart.) Mart. & 4 & 4 & 3 & 0 & 0 & 3 & 1 & 0 & 0 & 1 & 0,00 & 0,00 & 0,00 & 0,00 \\
\hline 2,08 & Hirtella sp. & 4 & 4 & 2 & 0 & 0 & 2 & 2 & 0 & 0 & 2 & 0,00 & 0,00 & 0,00 & 0,00 \\
\hline 1,87 & $\begin{array}{l}\text { Sclerolobium paniculatum } \\
\text { (Mart. ex Tul.) Benth. }\end{array}$ & 4 & 4 & 2 & 0 & 0 & 2 & 2 & 0 & 0 & 2 & 0,00 & 0,00 & 0,00 & 0,00 \\
\hline 2,17 & Tabebuia vellosoi Toledo & 4 & 4 & 2 & 0 & 0 & 2 & 2 & 0 & 0 & 2 & 0,00 & 0,00 & 0,00 & 0,00 \\
\hline 1,92 & $\begin{array}{l}\text { Unonopsis guatterioides } \\
\text { (A. DC.) R.E. Fr. }\end{array}$ & 4 & 4 & - & - & - & - & 4 & 0 & 0 & 4 & - & 0,00 & - & 0,00 \\
\hline 2,24 & Vitex polygama Cham. & 4 & 4 & 2 & 0 & 0 & 2 & 2 & 0 & 0 & 2 & 0,00 & 0,00 & 0,00 & 0,00 \\
\hline 1,80 & $\begin{array}{l}\text { Acrocomia aculeata } \\
\text { (Jacq.) Lodd. ex Mart. }\end{array}$ & 3 & 3 & - & - & - & - & 3 & 0 & 0 & 3 & - & 0,00 & - & 0,00 \\
\hline 2,17 & Astrocaryum sp. & 3 & 3 & 2 & 0 & 0 & 2 & 1 & 0 & 0 & 1 & 0,00 & 0,00 & 0,00 & 0,00 \\
\hline
\end{tabular}


Tabela 1. Continuação.

\begin{tabular}{|c|c|c|c|c|c|c|c|c|c|c|c|c|c|c|c|}
\hline \multirow{3}{*}{$\begin{array}{l}\text { Intervalo } \\
\text { entre T1 e } \\
\text { T2 (anos) }\end{array}$} & \multirow{3}{*}{ Espécies } & \multicolumn{10}{|c|}{ Número de Indivíduos } & \multicolumn{4}{|c|}{ Parâmetros de Dinâmica } \\
\hline & & \multicolumn{2}{|c|}{ Área Total } & \multicolumn{4}{|c|}{ Q1 } & \multicolumn{4}{|c|}{ Q2 } & \multicolumn{2}{|c|}{$\mathrm{M}(\%)$} & \multicolumn{2}{|c|}{$\mathrm{R}(\%)$} \\
\hline & & $\mathrm{N}_{1}$ & $\mathrm{~N}_{2}$ & $\mathrm{~N}_{1}$ & $\mathrm{~N}_{\mathrm{m}}$ & $\mathrm{N}_{\mathrm{r}}$ & $\mathrm{N}_{2}$ & $\mathrm{~N}_{1}$ & $\mathrm{~N}_{\mathrm{m}}$ & $\mathrm{N}_{\mathrm{r}}$ & $\mathrm{N}_{2}$ & Q1 & Q2 & Q1 & Q2 \\
\hline 1,94 & Curatella americana $\mathrm{L}$. & 3 & 3 & 1 & 0 & 0 & 1 & 2 & 0 & 0 & 2 & 0,00 & 0,00 & 0,00 & 0,00 \\
\hline 1,80 & Diptychandra aurantiaca Tul. & 3 & 3 & 2 & 0 & 0 & 2 & 1 & 0 & 0 & 1 & 0,00 & 0,00 & 0,00 & 0,00 \\
\hline 1,89 & Indeterminada 02 & 3 & 3 & - & - & - & - & 3 & 0 & 0 & 3 & - & 0,00 & - & 0,00 \\
\hline 1,80 & Jacaranda brasiliana (Lam.) Pers. & 3 & 3 & 2 & 0 & 0 & 2 & 1 & 0 & 0 & 1 & 0,00 & 0,00 & 0,00 & 0,00 \\
\hline 2,01 & Rapanea umbellata (Mart.) Mez & 3 & 3 & 2 & 0 & 0 & 2 & 1 & 0 & 0 & 1 & 0,00 & 0,00 & 0,00 & 0,00 \\
\hline 1,93 & Cecropia pachystachya Trécul & 3 & 2 & 2 & 1 & 0 & 1 & 1 & 0 & 0 & 1 & - & 0,00 & 0,00 & 0,00 \\
\hline 1,89 & Guatteria sp. & 3 & 2 & 1 & 1 & 0 & 0 & 2 & 0 & 0 & 2 & - & 0,00 & 0,00 & 0,00 \\
\hline 2,18 & Inga sessilis (Vell.) Mart. & 3 & 2 & 2 & 0 & 0 & 2 & 1 & 1 & 0 & 0 & 0,00 & - & 0,00 & 0,00 \\
\hline 1,89 & Licania kunthiana Hook. f. & 3 & 2 & - & - & - & - & 3 & 1 & 0 & 1 & - & - & - & 0,00 \\
\hline 1,89 & Roupala montana Aubl. & 3 & 2 & 2 & 1 & 0 & 1 & 1 & 0 & 0 & 1 & - & 0,00 & 0,00 & 0,00 \\
\hline 2,34 & Terminalia argentea Mart. & 3 & 1 & - & - & - & - & 3 & 2 & 0 & 1 & - & - & - & 0,00 \\
\hline 1,89 & Hirtella glandulosa Spreng. & 2 & 2 & - & - & - & - & 2 & 0 & 0 & 2 & - & 0,00 & - & 0,00 \\
\hline 1,91 & Myrcia fallax (Rich.) DC. & 2 & 2 & - & - & - & - & 2 & 1 & 1 & 2 & - & - & - & - \\
\hline 1,84 & Tapura amazonica Poepp. & 2 & 1 & 2 & 1 & 0 & 1 & - & - & - & - & - & - & 0,00 & - \\
\hline 1,89 & Amaioua guianensis Hemsl. & 1 & 1 & - & - & - & - & 1 & 0 & 0 & 1 & - & 0,00 & - & 0,00 \\
\hline 1,80 & Buchenavia tomentosa Eichler & 1 & 1 & - & - & - & - & 1 & 0 & 0 & 1 & - & 0,00 & - & 0,00 \\
\hline 1,88 & Mabea fistulifera Mart. & 1 & 1 & 1 & 0 & 0 & 1 & - & - & - & - & 0,00 & - & 0,00 & - \\
\hline 1,89 & Micropholis rigida Pierre & 1 & 1 & - & - & - & - & 1 & 0 & 0 & 1 & - & 0,00 & - & 0,00 \\
\hline 1,91 & $\begin{array}{l}\text { Pseudobombax tomentosum } \\
\text { (Mart. \& Zucc.) Robyns }\end{array}$ & 1 & 1 & - & - & - & - & 1 & 0 & 0 & 1 & - & 0,00 & - & 0,00 \\
\hline 1,97 & Qualea parviflora Mart. & 1 & 1 & 1 & 0 & 0 & 1 & - & - & - & - & 0,00 & - & 0,00 & - \\
\hline 1,89 & Sclerolobium sp. & 1 & 1 & 1 & 0 & 0 & 1 & - & - & - & - & 0,00 & - & 0,00 & - \\
\hline 1,89 & Siparuna guianensis Aubl. & 1 & 1 & 1 & 0 & 0 & 1 & - & - & - & - & 0,00 & - & 0,00 & - \\
\hline 1,89 & Diospyros sericea A. DC. & 1 & 0 & 1 & 1 & 0 & 0 & - & - & - & - & - & 0,00 & 0,00 & 0,00 \\
\hline 2,38 & Miconia albicans (Sw.) Triana & 1 & 0 & 1 & 1 & 0 & 0 & - & - & - & - & - & - & 0,00 & - \\
\hline 2,02 & Total & 2331 & 2144 & 1071 & 112 & 15 & 974 & 1260 & 100 & 10 & 1170 & 5,30 & 3,99 & 0,76 & 0,42 \\
\hline
\end{tabular}

$\pm 5,75$ ind.parcela $\left.{ }^{-1}\right)$ do que em Q1 $\left(11,9 \pm 5,14\right.$ ind.parcela $\left.^{-1}\right)$ $(\mathrm{t}=-2,632 ; \mathrm{gl}=178 ; \mathrm{p}=0,009)$. A diminuição na densidade de plantas entre T1 e T2 foi significativa tanto para Q1 $(\mathrm{t}=$ 5,309; $\mathrm{gl}=89 ; \mathrm{p}<0,001)$ como para Q2 $(\mathrm{t}=6,867 ; \mathrm{gl}=89$; $p<0,001)$. Houve ainda uma interação significativa entre a densidade e o tratamento $\left(F_{1 ; 176}=7,708 ; p=0,006\right)$, indicando que a relação entre densidade inicial e final diferiu entre Q1 e Q2, ou seja, a diminuição na densidade entre T1 e T2, diferiu entre os tratamentos Q1 e Q2. A proporção de indivíduos que morreram foi maior no tratamento Q1 do que no tratamento Q2 $\left(\chi^{2}=12,101 ; \mathrm{gl}=1 ; \mathrm{p}<0,001\right)$.

Em T1, a área basal total da comunidade foi $43,58 \mathrm{~m}^{2} \mathrm{e}$ em T2, 43,96 $\mathrm{m}^{2}$, sendo constatado um acréscimo de $0,38 \mathrm{~m}^{2}$ devido ao crescimento dos sobreviventes e recrutamento de alguns indivíduos (Tab. 2). A área basal inicial não diferiu entre Q1 e Q2 ( $\mathrm{t}=0,599 ; \mathrm{gl}=178 ; \mathrm{p}=0,55)$. Considerando apenas os indivíduos presentes em T1 e T2 (sobreviventes), houve um acréscimo de área basal no tratamento Q2 $(\mathrm{t}=$
$-2,747 ; \mathrm{gl}=89 ; \mathrm{p}=0,007)$, mas não em $\mathrm{Q} 1(\mathrm{t}=-1,320 ; \mathrm{gl}=89$; $\mathrm{p}=0,190)$. A relação entre a área basal inicial e final foi similar em Q1 e Q2 (ANCOVA; interação $\mathrm{F}_{1: 176}=0,121$; $\mathrm{p}=0,729$; tratamento $\left.\mathrm{F}_{1 ; 177}=0,533 ; \mathrm{p}=0,466\right)$.

A comparação entre Q1 e Q2 para as taxas de mortalidade $(\mathrm{t}=1,09 ; \mathrm{gl}=156 ; \mathrm{p}=0,27)$, recrutamento $(\mathrm{t}=1,51$; $\mathrm{gl}=105 ; \mathrm{p}=0,13)$, mudança $(\mathrm{t}=0,14 ; \mathrm{gl}=178 ; \mathrm{p}=0,88) \mathrm{e}$ rotatividade $(\mathrm{t}=1,77 ; \mathrm{gl}=142 ; \mathrm{p}=0,08)$ para número de indivíduos e as taxas de perda $(\mathrm{t}=0,11 ; \mathrm{gl}=178 ; \mathrm{p}=0,90)$, ganho $(\mathrm{t}=0,96 ; \mathrm{gl}=109 ; \mathrm{p}=0,33)$, mudança $(\mathrm{t}=0,66 ; \mathrm{gl}=$ $178 ; \mathrm{p}=0,50)$ e rotatividade $(\mathrm{t}=0,59 ; \mathrm{gl}=145 ; \mathrm{p}=0,56)$ para área basal não mostraram diferenças significativas (Tab. 2).

Não houve diferenças na distribuição do número de indivíduos por classes de diâmetro entre $\mathrm{T} 1 \mathrm{e} \mathrm{T} 2$, tanto em Q1 $(\mathrm{D}=2,85 ; \mathrm{gl}=2 ; \mathrm{p}=0,24)$ como em $\mathrm{Q} 2(\mathrm{D}=2,10 ; \mathrm{gl}$ $=2 ; p=0,34)$. No entanto, houve diferenças significativas entre Q1 e Q2 em T1 $(\mathrm{D}=12,22 ; \mathrm{gl}=2 ; \mathrm{p}=0,002)$ e T2 $(\mathrm{D}=14,11 ; \mathrm{gl}=2 ; \mathrm{p}=0,0009)$. Também não houve diferenças 
Tabela 2. Parâmetros de dinâmica calculados com base no número de indivíduos e na área basal da comunidade arbórea da floresta semidecídua do Parque Estadual da Serra Azul, Barra do Garças, MT. Q1 = área queimada uma vez; Q2 = área queimada duas vezes; $\mathrm{T} 1$ = primeiro levantamento (realizado entre outubro/2006 e maio/2007); T2 = segundo levantamento (realizado em março/2009).

\begin{tabular}{|c|c|c|c|}
\hline & $\begin{array}{c}\text { Amostra } \\
\text { Total }\end{array}$ & Q1 & Q2 \\
\hline \multicolumn{4}{|c|}{ Número de indivíduos } \\
\hline Número de espécies inicial & 102 & 84 & 95 \\
\hline Número de espécies final & 100 & 81 & 93 \\
\hline Diversidade de Shannon (H') T1 & 3,77 & 3,56 & 3,80 \\
\hline Diversidade de Shannon (H') T2 & 3,77 & 3,57 & 3,80 \\
\hline Número de indivíduos inicial & 2331 & 1071 & 1260 \\
\hline Número de indivíduos final & 2144 & 974 & 1170 \\
\hline Indivíduos sobreviventes & 2119 & 959 & 1160 \\
\hline Indivíduos mortos & 212 & 112 & 100 \\
\hline Indivíduos recrutas & 25 & 15 & 10 \\
\hline Mortalidade (M) \% & 4,59 & 5,30 & 3,99 \\
\hline Recrutamento (R) \% & 0,58 & 0,76 & 0,42 \\
\hline Mudança $\left(\mathrm{Ch}_{\mathrm{N}}\right) \%$ & $-4,04$ & $-4,57$ & $-3,58$ \\
\hline Rotatividade $\left(\mathrm{T}_{\mathrm{N}}\right) \%$ & 2,58 & 3,02 & 2,20 \\
\hline \multicolumn{4}{|c|}{ Área basal } \\
\hline Área basal inicial $\left(\mathrm{m}^{2}\right)$ & 43,58 & 22,33 & 21,25 \\
\hline Área basal final $\left(\mathrm{m}^{2}\right)$ & 43,96 & 22,56 & 21,40 \\
\hline Área basal morta $\left(\mathrm{m}^{2}\right)$ & 1,73 & 0,94 & 0,79 \\
\hline Área basal decrescida $\left(\mathrm{m}^{2}\right)$ & 1,06 & 0,40 & 0,66 \\
\hline Área basal ganha $\left(\mathrm{m}^{2}\right)$ & 3,11 & 1,53 & 1,58 \\
\hline Área basal recrutada $\left(\mathrm{m}^{2}\right)$ & 0,06 & 0,04 & 0,02 \\
\hline Perda (P) \% & 3,22 & 3,00 & 3,44 \\
\hline Ganho (G) \% & 3,63 & 3,49 & 3,76 \\
\hline Mudança $\left(\mathrm{Ch}_{\mathrm{AB}}\right) \%$ & 0,43 & 0,50 & 0,33 \\
\hline Rotatividade $\left(\mathrm{T}_{\mathrm{AB}}\right) \%$ & 3,42 & 3,25 & 3,60 \\
\hline
\end{tabular}

entre a frequência de indivíduos vivos observada em T2 e a frequência de indivíduos vivos esperada tanto em Q1 como em Q2 ( $=2,60 ; \mathrm{gl}=2 ; \mathrm{p}=0,27 ; \mathrm{D}=1,37 ; \mathrm{gl}=2$; $\mathrm{p}=0,50$ respectivamente). Já a frequência de indivíduos mortos observada e a frequência de indivíduos mortos esperada foram significativamente diferentes em Q1 e Q2 $(\mathrm{D}=10,68 ; \mathrm{gl}=2 ; \mathrm{p}=0,004$ e $\mathrm{D}=15,08 ; \mathrm{gl}=2 ; \mathrm{p}=0,0005$, respectivamente) sendo maior que o esperado na primeira classe e menor nas demais (Tab. 3).

As comparações referentes às distribuições da área basal em classes de diâmetro não apontaram diferenças entre T1 e T2 em Q1 ( $=0,03 ; \mathrm{gl}=2 ; \mathrm{p}=0,98)$ e em Q2 ( $=0,03$; gl $=2 ; \mathrm{p}=0,98)$, bem como não houve diferenças significativas entre Q1 e Q2 em T1 ( $=1,27 ; \mathrm{gl}=2 ; \mathrm{p}=0,52)$ e em T2 $(\mathrm{D}=1,28 ; \mathrm{gl}=2 ; \mathrm{p}=0,52)$. Da mesma forma, não houve diferenças significativas na frequência de área basal viva observada em T2 e a área basal viva esperada tanto em Q1 $(\mathrm{D}=0,14 ; \mathrm{gl}=2 ; \mathrm{p}=0,92)$ como em $\mathrm{Q} 2(\mathrm{D}=0,03 ; \mathrm{gl}=2$; $\mathrm{p}=0,98)$. Como os valores de área basal para os indivíduos mortos entre T1 e T2 foram muito pequenos, não foi possível comparar a área basal morta em T2 com a área basal morta esperada para esse levantamento (Tab. 3).

Por outro lado, a distribuição do número de indivíduos por classes de altura foi diferente entre T1 e T2 em Q1 $(\mathrm{D}=25,52 ; \mathrm{gl}=2 ; \mathrm{p}<0,0001)$ e $\mathrm{Q} 2(\mathrm{D}=45,90 ; \mathrm{gl}=2$; $\mathrm{p}<0,0001)$, mas não houve diferenças significativas entre Q1 e Q2 em T1 ( $=0,74 ; \mathrm{gl}=2 ; \mathrm{p}=0,69)$ e T2 ( $=3,89$; $\mathrm{gl}=$ $2 ; \mathrm{p}=0,14$ ) (Tab. 4). A distribuição de frequência do número de indivíduos vivos observada em T2 foi significativamente diferente da esperada, tanto em Q1 ( $\mathrm{D}=24,39$; $\mathrm{gl}=2$; $\mathrm{p}<0,0001)$ como em Q2 ( $=44,30 ; \mathrm{gl}=2 ; \mathrm{p}<0,0001)$. Ao passo que a frequência de indivíduos mortos observada em T2 também foi diferente da frequência de indivíduos mortos esperada, mas apenas em Q1 $(\mathrm{D}=8,64 ; \mathrm{gl}=2 ; \mathrm{p}=0,01)$ e não em Q2 ( $\mathrm{D}=3,92 ; \mathrm{gl}=2 ; \mathrm{p}=0,14)$ (Tab. 4).

\section{Discussão}

Os resultados contrariaram várias das hipóteses levantadas inicialmente. Ao contrário do esperado, o presente estudo mostrou maior riqueza e diversidade de espécies nas áreas da floresta queimadas duas vezes do que nas queimadas uma vez. Alguns estudos já verificaram diminuição na riqueza de espécies em áreas que sofreram perturbações (Nascimento et al. 1999), no entanto, a intensidade e a frequência desses distúrbios podem contribuir tanto para diminuição como para o aumento da riqueza da comunidade. Isso está relacionado à severidade das perturbações, sendo que as extremas ocasionam a perda de espécies. Por outro lado, perturbações de intensidade intermediária, que ocorrem em áreas em estágio sucessional avançado, podem ocasionar um aumento na diversidade local. A maior riqueza de espécies ocorre quando perturbações recorrentes permitem a manutenção de diversos estágios sucessionais dentro de uma mesma vegetação (Sheil \& Burslem 2003). Embora o fogo possa ocasionar a eliminação de espécies sensíveis às chamas e promover a progressiva simplificação da composição florística, como consequência da morte de indivíduos (Felfili et al. 2000; Medeiros \& Miranda 2005), ele também pode promover um aumento na riqueza de espécies, o qual estaria relacionado à abertura de clareiras que favorece o recrutamento de espécies pioneiras e secundárias (Paula et al. 2004). Silva et al. (2005), monitorando a dinâmica em uma floresta semidecídua em Ibiturana (MG), encontraram aumento na diversidade e riqueza de espécies de árvores dois anos após o incêndio, provavelmente devido ao acréscimo de espécies pioneiras nas áreas abertas pelo fogo. Sendo assim, nossos resultados sobre a dinâmica pós-fogo na mata semidecídua do PESA parecem se adequar a hipótese de distúrbio intermediário.

No PESA, a redução da densidade de árvores foi uma consequência do grande número de indivíduos mortos contraposto com o baixo recrutamento. Inicialmente, esperava-se encontrar menor densidade em trechos com dois eventos 
Tabela 3. Dinâmica por classes de diâmetro do componente arbóreo da floresta semidecídua localizada no Parque Estadual da Serra Azul, Barra do Garças, MT. Q1 = área queimada uma vez; Q2 = área queimada duas vezes; T1 = primeiro levantamento (outubro/2006 a maio/2007); T2 = segundo levantamento (março/2009); Esp. 1 = freqüência esperada de indivíduos ou de área basal dos vivos em T2; Mortos. = número de indivíduos ou área basal dos mortos entre T1 e T2; Esp. 2 = freqüência esperada de indivíduos ou de área basal dos mortos entre T1 e T2; Recrutas = número de indivíduos ou de área basal dos recrutados entre T1 e T2; Ingressantes = recrutas + imigrantes; Egressos = mortos + emigrantes; Obs. = observado.

\begin{tabular}{|c|c|c|c|c|c|c|c|c|c|c|c|c|c|c|c|c|c|c|c|c|}
\hline \multirow{4}{*}{$\begin{array}{l}\text { Classes de } \\
\text { diâmetro }\end{array}$} & \multicolumn{20}{|c|}{ Número de indivíduos } \\
\hline & \multicolumn{6}{|c|}{ Vivos } & \multicolumn{4}{|c|}{ Mortos } & \multicolumn{2}{|c|}{ Imigrantes } & \multicolumn{2}{|c|}{ Recrutas } & \multicolumn{2}{|c|}{ Ingressantes. } & \multicolumn{2}{|c|}{ Emigrantes. } & \multicolumn{2}{|c|}{ Egressos. } \\
\hline & \multicolumn{3}{|c|}{ Q1 } & \multicolumn{3}{|c|}{ Q2 } & \multicolumn{2}{|c|}{ Q1 } & \multicolumn{2}{|c|}{ Q2 } & \multirow{2}{*}{ Q1 } & \multirow{2}{*}{ Q2 } & \multirow{2}{*}{ Q1 } & \multirow{2}{*}{ Q2 } & \multirow{2}{*}{ Q1 } & \multirow{2}{*}{ Q2 } & \multirow{2}{*}{ Q1 } & \multirow{2}{*}{ Q2 } & \multirow{2}{*}{ Q1 } & \multirow{2}{*}{ Q2 } \\
\hline & $\mathrm{T} 1$ & $\mathrm{~T} 2$ & Esp1. & $\mathrm{T} 1$ & $\mathrm{~T} 2$ & Esp1. & Obs & Esp.2 & Obs & Esp.2 & & & & & & & & & & \\
\hline 4,7 나 10 & 437 & 361 & 397 & 502 & 438 & 446 & 70 & 46 & 67 & 40 & 8 & 14 & 15 & 10 & 23 & 24 & 29 & 21 & 99 & 88 \\
\hline $10-20$ & 446 & 419 & 406 & 612 & 577 & 568 & 37 & 47 & 32 & 49 & 30 & 31 & 0 & 0 & 30 & 31 & 20 & 34 & 57 & 66 \\
\hline $20-40$ & 171 & 177 & 156 & 135 & 142 & 125 & 5 & 18 & 1 & 11 & 13 & 21 & 0 & 0 & 13 & 21 & 2 & 13 & 7 & 14 \\
\hline $40 \vdash 80$ & 16 & 16 & 15 & 11 & 13 & 10 & 0 & 2 & 0 & 1 & 0 & 3 & 0 & 0 & 0 & 3 & 0 & 1 & 0 & 1 \\
\hline$>80$ & 1 & 1 & 1 & 0 & 0 & 0 & 0 & 0 & 0 & 0 & 0 & 0 & 0 & 0 & 0 & 0 & 0 & 0 & 0 & 0 \\
\hline \multirow[t]{2}{*}{ Total } & 1071 & 974 & 974 & 1260 & 1170 & 1170 & 112 & 112 & 100 & 100 & 51 & 69 & 15 & 10 & 66 & 79 & 51 & 69 & 163 & 169 \\
\hline & \multicolumn{20}{|c|}{ Área basal $\left(\mathrm{m}^{2}\right)$} \\
\hline & \multicolumn{6}{|c|}{ Vivos } & \multicolumn{4}{|c|}{ Mortos } & \multicolumn{2}{|c|}{ Imigrantes } & \multicolumn{2}{|c|}{ Recrutas } & Ingres & santes. & Emigr & antes. & Egre & ssos. \\
\hline $\begin{array}{l}\text { Classes de } \\
\text { diâmetro }\end{array}$ & & Q1 & & & Q2 & & & & & & & & & & & & & & & \\
\hline & $\mathrm{T} 1$ & $\mathrm{~T} 2$ & Esp.1 & $\mathrm{T} 1$ & $\mathrm{~T} 2$ & Esp.1 & Obs. & Esp.2 & Obs. & Esp.2 & Q1 & Q2 & Q1 & Q2 & Q1 & Q2 & Q1 & Q2 & Q1 & Q2 \\
\hline 4,7 ㄴ 10 & 1,88 & 1,61 & 1,90 & 2,23 & 2,00 & 2,24 & 0,26 & 0,08 & 0,27 & 0,08 & 0,05 & 0,09 & 0,04 & 0,02 & 0,09 & 0,11 & 0,48 & 0,17 & 0,74 & 0,44 \\
\hline $10 \vdash 20$ & 7,03 & 6,76 & 7,11 & 9,90 & 9,60 & 9,97 & 0,47 & 0,30 & 0,46 & 0,37 & 0,29 & 0,42 & 0 & 0 & 0,29 & 0,42 & 0,57 & 0,79 & 1,04 & 1,25 \\
\hline $20 \vdash 40$ & 9,43 & 10,06 & 9,53 & 6,84 & 7,13 & 6,89 & 0,21 & 0,40 & 0,06 & 0,25 & 0,52 & 0,71 & 0 & 0 & 0,52 & 0,71 & 0,05 & 0,66 & 0,25 & 0,72 \\
\hline $40 \vdash 80$ & 2,96 & 3,00 & 2,99 & 2,29 & 2,66 & 2,31 & 0,00 & 0,12 & 0 & 0,09 & 0,22 & 0,41 & 0 & 0 & 0,22 & 0,41 & 0 & 0,01 & 0,00 & 0,01 \\
\hline$>80$ & 1,02 & 1,13 & 1,03 & 0 & 0 & 0 & 0,00 & 0,04 & 0 & 0 & 0 & 0 & 0 & 0 & 0 & 0 & 0 & 0 & 0,00 & 0 \\
\hline Total & 22,3 & 22,5 & 22,5 & 21,2 & 21,4 & 21,4 & 0,94 & 0,94 & 0,79 & 0,79 & 1,08 & 1,63 & 0,04 & 0,02 & 1,12 & 1,65 & 1,09 & 1,63 & 2,02 & 2,42 \\
\hline
\end{tabular}

Tabela 4. Dinâmica por classes de altura do componente arbóreo da floresta semidecídua localizada no Parque Estadual da Serra Azul, Barra do Garças, MT. Q1 = área queimada uma vez; Q2 = área queimada duas vezes; T1 = primeiro levantamento (outubro/2006 a maio/2007); T2 = segundo levantamento (março/2009); Esp. 1 = freqüência esperada de indivíduos vivos em T2; Mortos = número de indivíduos dos mortos entre T1 e T2; Esp. 2 = freqüência esperada de indivíduos mortos entre T1 e T2; Recrutas = número de indivíduos recrutados entre T1 e T2; Ingressantes = recrutas + imigrantes; Egressos = mortos + emigrantes; Obs. = observado.

\begin{tabular}{|c|c|c|c|c|c|c|c|c|c|c|c|c|c|c|c|c|c|c|c|c|}
\hline \multirow{4}{*}{$\begin{array}{c}\text { Classes } \\
\text { de altura }\end{array}$} & \multicolumn{20}{|c|}{ Número de indivíduos } \\
\hline & \multicolumn{6}{|c|}{ Vivos } & \multicolumn{4}{|c|}{ Mortos } & \multicolumn{2}{|c|}{ Imigrantes } & \multicolumn{2}{|c|}{ Recrutas } & \multicolumn{2}{|c|}{ Ingressantes } & \multicolumn{2}{|c|}{ Emigrantes } & \multicolumn{2}{|c|}{ Egressos } \\
\hline & \multicolumn{3}{|c|}{ Q1 } & \multicolumn{3}{|c|}{ Q2 } & \multicolumn{2}{|c|}{ Q1 } & \multicolumn{2}{|c|}{ Q2 } & \multirow{2}{*}{ Q1 } & \multirow{2}{*}{ Q2 } & \multirow{2}{*}{ Q1 } & \multirow{2}{*}{ Q2 } & \multirow{2}{*}{ Q1 } & \multirow{2}{*}{ Q2 } & \multirow{2}{*}{ Q1 } & \multirow{2}{*}{ Q2 } & \multirow{2}{*}{ Q1 } & \multirow{2}{*}{ Q2 } \\
\hline & $\mathrm{T} 1$ & $\mathrm{~T} 2$ & Esp1. & $\mathrm{T} 1$ & $\mathrm{~T} 2$ & Esp1. & Obs. & Esp.2 & Obs. & Esp.2 & & & & & & & & & & \\
\hline 아 5 & 77 & 54 & 70 & 72 & 56 & 67 & 17 & 8 & 18 & 6 & 18 & 21 & 14 & 9 & 32 & 30 & 38 & 28 & 55 & 46 \\
\hline 5 ㄴ 10 & 464 & 332 & 422 & 587 & 395 & 545 & 62 & 49 & 49 & 47 & 75 & 108 & 1 & 1 & 76 & 109 & 145 & 251 & 207 & 300 \\
\hline 10 - 15 & 376 & 339 & 342 & 418 & 470 & 388 & 26 & 39 & 26 & 33 & 142 & 282 & 0 & 0 & 142 & 282 & 153 & 204 & 179 & 230 \\
\hline 15 ㄴ 20 & 115 & 229 & 105 & 119 & 239 & 111 & 5 & 12 & 7 & 9 & 152 & 189 & 0 & 0 & 152 & 189 & 33 & 62 & 38 & 69 \\
\hline$>20$ & 39 & 20 & 35 & 64 & 10 & 59 & 2 & 4 & 0 & 5 & 13 & 8 & 0 & 0 & 13 & 8 & 31 & 63 & 33 & 63 \\
\hline Total & 1071 & 974 & 974 & 1260 & 1170 & 1170 & 112 & 112 & 100 & 100 & 400 & 608 & 15 & 10 & 415 & 618 & 400 & 608 & 512 & 708 \\
\hline
\end{tabular}

de fogo do que em nos trechos com apenas uma queimada. No entanto, o trecho queimado uma vez apresentou maior proporção de mortos que o trecho queimado duas vezes. A redução da densidade menos acentuada onde queimou duas vezes pode ser explicada pelo fato da inflamabilidade da floresta tender a diminuir em locais onde ocorrem queimadas repetidas, em função do consumo do material combustível acumulado, especialmente serapilheira. Balch et al. (2008), ao verificarem os efeitos de incêndios sucessivos em uma floresta amazônica, observaram que parcelas submetidas a queimadas anuais ao longo de três anos, apresentaram uma diminuição da quantidade de serapilheira após a segunda 
queimada, o que contribuiu para que a intensidade do fogo e a área atingida por ele fossem menor. Esses mesmos autores confirmaram essa hipótese quando detectaram um aumento na quantidade de combustível, intensidade do fogo e área queimada em parcelas que tiveram apenas um ou nenhum evento de fogo durante os três anos de experimento. Sob essas circunstâncias, um evento de fogo em local queimado recentemente pode causar menor mortalidade do que um incêndio que ocorre num local que há muito tempo não queima. Além disso, em áreas onde queimadas são menos frequentes, pode haver mais indivíduos de espécies sensíveis ao fogo. Assim, quando ocorre uma queimada, a mortalidade nesses sítios é maior.

No nosso estudo, mesmo com o baixo recrutamento e diminuição da densidade, a floresta apresentou acréscimo de área basal devido ao crescimento dos sobreviventes. Isso difere do que foi encontrado em uma floresta semidecídua atingida por fogo em Ibiturana (MG) e que teve a dinâmica monitorada por Silva et al. (2005) alguns anos após o distúrbio. Apesar desses autores terem encontrado diminuição da densidade por hectare, não encontraram diferença em área basal de árvores vivas por hectare entre os inventários, sendo que somente para árvores mortas a área basal foi maior. O acréscimo de área basal, associado ao decréscimo na densidade, já foi observado em outras florestas que não foram atingidas por queimadas. Por exemplo, Guilherme et al. (2004) encontraram um decréscimo de $10,96 \%$ da densidade e um acréscimo de $33,71 \%$ na área basal e Werneck et al. (2000) verificaram uma diminuição significativa da densidade $(10,2 \%)$ decorrente das elevadas taxas de mortalidade, em contraponto com um aumento de $1,5 \%$ da área basal. De acordo com Chagas et al. (2001), o aumento líquido da área basal dos indivíduos, apesar da redução da densidade, é compatível com o processo de autodesbaste, no qual a dimensão média e a biomassa total dos indivíduos aumentam à medida que a densidade decresce. $\mathrm{O}$ autodesbate está frequentemente associado às fases avançadas de regeneração pós-distúrbios (Oliveira Filho et al. 2007; Werneck \& Franceschinelli 2004) e ocorre como consequência da competição que elimina os indivíduos menores. No PESA, a redução da densidade foi claramente relacionada ao fogo, um distúrbio externo que atuou como agente de desbaste de indivíduos pertencentes às menores classes de tamanho, que são aqueles mais vulneráveis ao fogo. A redução da densidade de indivíduos menores favoreceu o crescimento dos sobreviventes, o que pode ser observado pelo aumento da área basal de árvores vivas.

No PESA, não foram encontradas diferenças significativas entre trechos queimados uma vez (Q1) e trechos com queimadas recorrentes (Q2) tanto para taxas anuais de mortalidade quanto para recrutamento. Esses resultados rejeitaram a nossa hipótese que previa maior mortalidade em função da maior frequência de queimadas. No entanto, nossos resultados revelaram desequilíbrio entre taxas de mortalidade e recrutamento, tanto em Q1 quanto Q2. Isso indica que a floresta semidecídua do PESA está instável independente da frequência das queimadas ocorridas nas duas áreas, o que contraria parcialmente a nossa hipótese que supunha maior instabilidade na área com mais eventos de queimadas. Esse padrão de dinâmica tem sido observado em monitoramentos de curto prazo nas florestas perturbadas por diversos fatores. Oliveira-Filho et al. (2007) encontraram taxa de mortalidade significativamente maior do que a taxa de recrutamento, comparando a borda e o interior de uma floresta fragmentada na Serra da Mantiqueira. Appolinário et al. (2005) e Guilherme et al. (2004) também registraram taxas de mortalidade superiores às taxas de recrutamento em florestas estacionais semideciduais que passaram por inundações periódicas. Silva et al. (2011) estudando fragmentos florestais no Sul de Minas Gerais, constataram que a dinâmica após a enchente foi caracterizada por taxa de mortalidade superior à de recrutamento. Por outro lado, maiores taxas de recrutamento em relação à mortalidade só têm sido encontradas em florestas com estágios avançados de regeneração após o distúrbio (Oliveira-Filho et al. 1997). De maneira geral, em florestas tropicais não perturbadas, prevalece o balanço entre as taxas de mortalidade e recrutamento e as taxas de perda e ganho de área basal, o que mantém as populações numericamente constantes e a comunidade em equilíbrio dinâmico (Lieberman et al. 1985; Swaine et al. 1987; Lopes \& Schiavini 2007; Saiter et al. 2011).

Nossos resultados mostraram que o maior impacto do fogo foi sobre os estratos mais baixos da floresta, o que era esperado. Apesar de termos encontrado mortalidade dependente do tamanho, a estrutura diamétrica da floresta não foi alterada mesmo na área que queimou mais vezes. Resultados similares foram encontrados por Silva et al. (2011) que estudaram a dinâmica de fragmentos florestais após enchentes e verificaram a manutenção da estrutura diamétrica da comunidade, uma vez que a frequencia de indivíduos sobreviventes e de mortos nas classes diamétricas não diferiu no período monitorado. No PESA, por outro lado, a estrutura vertical foi modificada tanto em Q1 como Q2. A mortalidade em função do fogo é muito maior entre árvores de menor porte, uma vez que árvores maiores são mais resistentes ao contato com as chamas (Woods 1989; Nascimento et al. 2000). Alguns autores sugerem que indivíduos jovens apresentam cascas mais finas em relação às árvores maiores, o que pode ser uma das causas da mortalidade nessa classe (Uhl \& Kauffmann 1990; Hoffmann \& Solbrig 2003). Qualquer fonte adicional de estresse pode aumentar as taxas de mortalidade entre as árvores menores (Appolinário et al. 2005), dessa forma a ocorrência de queimadas em intervalos curtos impede que muitos indivíduos alcancem classes de tamanho capazes de resistir à morte (Hoffmann \& Solbrig 2003).

De uma forma geral, Q1 e Q2 tiveram comportamento muito similar em termos de dinâmica. As queimadas são historicamente frequentes no PESA. Talvez isso possa explicar a resiliência da vegetação frente aos distúrbios 
causados pelo fogo ou a eficiência em compensar a perda de biomassa, pois ambas as áreas possuem espécies e estrutura já previamente selecionadas pelo fogo e respondem de forma similar às queimadas.

Apesar da biomassa não ter sido fortemente impactada, pois o crescimento das árvores sobreviventes compensou a perda de biomassa dos indivíduos que morreram, os danos cumulativos nas árvores menores causados por queimadas recorrentes podem alterar, em longo prazo, a abundância e a estrutura vertical da vegetação.

\section{Agradecimentos}

A Coordenação de Aperfeiçoamento de Pessoal de Nível Superior (CAPES) pela concessão da bolsa de mestrado à primeira autora. Ao CNPq pela bolsa Produtividade em Pesquisa/2F (Processo No 503938/2009-2) ao FAG Guilherme. A Secretaria de Estado do Meio Ambiente de Mato Grosso (SEMA) pela permissão da realização dos trabalhos no Parque Estadual da Serra Azul (PESA).

\section{Referências Bibliográficas}

Appolinário, V.; Oliveira-Filho, A.T. \& Guilherme, F.A.G. 2005. Tree population and community dynamics in a Brazilian tropical semideciduous forest. Revista Brasileira de Botânica 28: 347-360.

Balch, J.; Nepstad, D.C.; Brando, P.M.; Curran, L.M.; Portela, O.; Carvalho Jr., O. \& Lefebvre, P. 2008. Negative fire feedback in a transitional forest of southeastern Amazonia. Global Change Biology 14: 2276-2287.

Bond, W.J. \& Wilgen, B.W. 1996. Fire and Plants. New York, Chapman $\&$ Hall.

Braga, F.M.S. \& Rezende, A.V. 2007. Dinâmica da vegetação arbórea da mata de galeria do Catetinho, Brasília-DF. Revista Cerne 13: 138-148.

Chagas, R.K.; Oliveira-Filho, A.T.; Van Den Berg, E. \& Scolforo, J.R.S. 2001. Dinâmica de populações arbóreas de um fragmento de floresta estacional semidecidual Montana em Lavras, Minas Gerais. Revista Árvore 25: 39-57.

Chiarucci, A.; Enright, N. J.; Perry, G. L. W.; Miller, B. P. B. \& Lamont, B. 2003. Performance of non-parametric species richness estimators in a high diversity plant community. Diversity and Distributions 9: 283-295

Cochrane, M.A. \& Schulze, M.D. 1999. Fire as a recurrent event in tropical forests of the eastern Amazon: effects on forest structure, biomass, and species composition. Biotropica 31: 2-16.

Denslow, J.S. 1987. Tropical rainforests gaps and tree species diversity. Annual Review of Ecology and Systematics 18: 431-451.

DeWalt, S.J.; Maliakal, S.K. \& Denslow, J.S. 2003. Changes in vegetation structure and composition along a tropical forest chronosequence: implications for wildlife. Forest Ecology and Management 6227: 1-13.

Felfili, J.M.; Rezende, A.V.; Silva Júnior, M.C. \& Silva, M.A. 2000. Changes in the floristic composition of cerrado sensu stricto in Brazil over a nine-year period. Journal of Tropical Ecology 16: 579-590.

FEMA. 2000. Fundação Estadual do Meio Ambiente do Estado de Mato Grosso. Diagnóstico Ambiental do Parque Estadual da Serra Azul, Barra do Garças, MT.

Guilherme, F.A.G.; Oliveira-Filho, A.T.; Appolinário, V. \& Bearzoti, E. 2004. Effects of flooding regime and woody bamboos on tree community dynamics in a section of tropical semideciduous forest in South-Eastern Brazil. Plant Ecology 174: 19-36.

Guimarães, J.C.C.; Van Den Berg, E.; Castro, G.C.; Machado. E.L.M. \& Oliveira-Filho, A.T. 2008. Dinâmica do componente arbustivo-arbóreo de uma floresta de galeria aluvial no planalto de Poços de Caldas, MG, Brasil. Revista Brasileira de Botânica 31: 621-632.
Higuchi, P.; Oliveira-Filho, A.T.; Silva, A.C.; Machado, E.L.M.; Santos, R.M. \& Pifano, D.S. 2008. Dinâmica da comunidade arbórea em um fragmento de floresta estacional semidecidual Montana em Lavras, Minas Gerais, em diferentes classes de solos. Revista Árvore 32: 417-426.

Hoffmann, W.A. \& Solbrig, O.T. 2003. The role of topkill in the differential response of savanna woody species to fire. Forest Ecology and Management 180: 273-286.

Holl, K.D. 1999. Tropical forest recovery and restoration. Tree 14: 378-379. Hutcheson, K. 1970. A test for comparing diversities based on the Shannon formula. Journal of Theoretical Biology 29: 151-154.

Hubbell, S.P.; Foster, R.B.; O’Brien, S.T.; Harns, K.E.; Condit, R.; Wechsler, B.; Wright, S.J. \& Loo-de-Lao, S. 1999. Light-gap disturbance, recruitment limitation, and tree diversity in a neotropical forest. Science 283: 554-557.

Ivanauskas, N.M.; Monteiro, R. \& Rodrigues, R.R. 2003. Alterations following a fire in a forest community of Alto Rio Xingu. Forest Ecology and Management 184: 239-250.

Keeley, J.E.; Lubin, D. \& Fotheringham, C.J. 2003. Fire and grazing impacts on plant diversity and alien plant invasions in the southern Sierra Nevada. Ecological Applications 13: 1355-1374.

Kennard, D.K.; Gould, K.; Putz, F.E.; Fredericksen, T.S. \& Morales, F. 2002. Effects of disturbance intensity on regeneration mechanisms in a tropical dry forest. Forest Ecology and Management 162: 197-208.

Korning, J. \& Balslev, H. 1994. Growth and mortality of trees in Amazonian tropical rain forest in Ecuador. Journal of Vegetation Science 4: 77-86

Lang, G.E. \& Knight, D.H. 1983. Tree growth, mortality, recruitment, and canopy gap formation during a 10 -year period in a tropical moist forest. Ecology 64: 1075-1080.

Laurance, W.F.; Ferreira, L.V.; Merona, J.M.R. \& Laurance, S.G. 1998. Rain forest fragmentation and the dynamics of Amazonian tree communities. Ecology 79: 2032-2040.

Laurance, W.F. 2003. Slow burn: the insidious effects of surface fires on tropical forests. Trends in Ecology and Evolution 18: 209-212.

Lewis, S.L.; Phillips, O.L.; Sheil, D.; Vinceti, B.; Baker, T.R.; Brown, S.; Graham, A.W.; Higuchi, N.; Hilbert, D.W.; Laurance, W.F.; Lejoly, J.; Malhi, Y.; Monteagudo, A.; Vargas, P.N.; Sonké, B.; Nur Supardi, M.N.; Terborgh, J.W. \& Martínez, R.V. 2004. Tropical forest tree mortality, recruitment and turnover rates: calculation, interpretation and comparison when census intervals vary. Journal of Ecology 92: 929-944.

Lieberman, D.; Lieberman, M.; Peralta, R. \& Hartshorn, G.S. 1985. Mortality patterns and stand turnover rates in a wet tropical forest in Costa Rica. Journal of Ecology 73: 915-924.

Lopes, S.F. \& Schiavini, I. 2007. Dinâmica da comunidade arbórea de mata de galeria da Estação Ecológica do Panga, Minas Gerais, Brasil. Acta Botanica Brasilica 21: 249-261.

Magurran, A.E. 1988. Ecological diversity and its measurement. Princeton, Princeton University

Medeiros, M.B. \& Miranda, H.S. 2005. Mortalidade pós-fogo em espécies lenhosas de campo sujo submetido a três queimadas prescritas anuais. Acta Botanica Brasilica 19: 493-500.

Melo, A.C.G.; Durigan, G. \& Gorenstein, M.R. 2007. Efeito do fogo sobre o banco de sementes em faixa de borda de floresta estacional semidecidual, SP, Brasil. Acta Botanica Brasilica 21: 927-934.

Nascimento, H.E.M.; Dias, A.S.; Tabanez, A.A.J. \& Viana, V.M. 1999. Estrutura e dinâmica de populações arbóreas de um fragmento de floresta estacional semidecidual na região de Piracicaba, SP. Revista Brasileira de Biologia 59: 329-342.

Nascimento, M.T.; Felfili, J.M.; Oliveira-Filho, A.T.; Fontes, M.A.; França, J.T.; Hay, J.D \& Gribel, R. 2000. Efeitos do fogo nas florestas: as queimadas em Roraima. Ciência Hoje 27: 40-43.

Oliveira-Filho, A.T.; Mello, J.M. \& Scolforo, J.R.S. 1997. Effects of past disturbance and edges on tree community structure and dynamics within a fragment of tropical semideciduous forest in south-eastern Brazil over a five year period (1987-1992). Plant Ecology 131:45-66.

Oliveira-Filho, A.T.; Carvalho, W.A.C.; Machado, E.L.M.; Higuchi, P.; Appolinário, V.; Castro, G.C.; Silva, A.C.; Santos, R.M.; Borges, L.F.; Corrêa, B.S. \& Alves, J.M. 2007. Dinâmica da comunidade e populações arbóreas da borda e interior de um remanescente florestal na Serra da Mantiqueira, Minas Gerais, em um intervalo de cinco anos (1999-2004). Revista Brasileira de Botânica 30: 149-161. 
Otterstrom, S.M. \& Schwartz, M.W. 2006. Responses to fire in selected tropical dry forest trees. Biotropica 38: 592-598.

Paiva, L.V.; Araújo, G.M. \& Pedroni, F. 2007. Structure and dynamics of a woody plant community of a tropical semi-deciduous seasonal forest in the "Estação Ecológica do Panga", municipality of Uberlândia, Minas Gerais, Brazil. Revista Brasileira de Botânica 30: 365-373.

Paula, A.; Silva, A.F.; De Marco JR, P.; Santos, F.A.M. \& Souza, A.L. 2004. Sucessão ecológica da vegetação arbórea em uma Floresta Estacional Semidecidual, Viçosa, MG, Brasil. Acta Botanica Brasilica 18: 407423.

Pirani, F.R.; Sanchez, M. \& Pedroni, F. 2009. Fenologia de uma comunidade arbórea em cerrado sentido restrito, Barra do Garças, MT. Acta Botanica Brasilica 23: 1096-1109.

R Development Core Team. 2007. R: A language and environment for statistical computing. R Foundation for Statistical Computing, Vienna, Austria. ISBN 3-900051-07-0, URL http://www.R-project.org.

Saiter, F.Z.; Guilherme, F.A.G.; Thomaz, L. \& Wendt, T. 2011. Tree changes in a mature rainforest with high diversity and endemism on the Brazilian coast. Biodiversity and Conservation 20: 1921-1949.

Silva, M.R. \& Araújo, G.M. 2009. Dinâmica da comunidade arbórea de uma floresta semidecidual em Uberlândia, MG, Brasil. Acta Botanica Brasilica 23: 49-56.

Silva, V.F.; Oliveira-Filho, A.T.; Venturin, N.; Carvalho, W.A.C. \& Gomes, J.B.V. 2005. Impacto do fogo no componente arbóreo de uma floresta estacional semidecídua no município de Ibituruna, MG, Brasil. Acta Botanica Brasilica 19: 701-716.

Silva, A.C.; van den Berg, E.; Higuchi, P. \& Nunes, M.H. 2011 Dinâmica de uma comunidade arbórea após enchente em fragmentos florestais no Sul e Minas Gerais. Revista Árvore 35: 883-893.
Sheil, D.; Jennings, S. \& Savill, P. 2000. Long-term permanent plot observations of vegetation dynamics in Budongo, a Ugandan rain. Journal of Tropical Ecology 16: 765-800.

Sheil, D. \& May, R.M. 1996. Mortality and recruitment rate evaluations in heterogeneous tropical forests. Journal of Ecology 84: 331-333.

Sheil, D. \& Burslem, D.F.R.P. 2003. Disturbing hypotheses in tropical forests. Trends in Ecology and Evolution 18: 18-26.

SPSS. 2000. Systat, version 10. SPSS Inc., San Francisco, CA.

Swaine, M.D.; Lieberman, D. \& Putz, F.E. 1987. The dynamics of tree populations in tropical forest: a review. Journal of Tropical Ecology 3: $359: 366$.

Swaine, M.D.; Lieberman, D. \& Hall, J.B. 1990. Structure and dynamics a tropical dry forest in Ghana. Vegetation 88: 31-51.

Taylor, D.; Hamilton, A.C.; Lewis, S.L. \& Nantale, G. 2008. Thirty-eight years of change in a tropical Forest: plot data from Mpanga Forest Reserve, Uganda. African Journal of Ecology 46: 655-667.

Uhl, C. \& Kauffman, J.B. 1990. Deforestation, fire susceptibility, and potential tree responses to fire in eastern Amazon. Ecology 71: 437-449.

Werneck, M. \& Franceschinelli, E.V. 2004. Dynamics of a dry forest fragment after the exclusion of human disturbance in southeastern Brazil. Plant Ecology 174: 337-346

Werneck, M.S.; Franceschinelli, E.V. \& Tameirão-Neto, E. 2000. Mudanças na florística e estrutura de uma floresta decídua durante um período de quatro anos (1994-1998), na região do Triângulo Mineiro, MG. Revista Brasileira de Botânica 23: 401-413.

Woods, P. 1989. Effects of logging, drought and fire on structure and composition of forests in Sabah, Malaysia. Biotropica 21: 290-298.

Zar, J.H. 1998. Biostatistical analysis. 4 ed. New Jersey, Prentice-Hall International Editions. 